\title{
STUDYING THE DYNAMICS OF BREAKDOWN OF THIN HORIZONTAL LIQUID LAYERS WITH LOCAL HEATING
}

\author{
Serafim Spesivtsev ${ }^{1,2, *}$, and Yuriy Lyulin ${ }^{1,3}$ \\ ${ }^{1}$ Kutateladze Institute of Thermophysics SB RAS, 630090 Novosibirsk, Russia \\ ${ }^{2}$ Novosibirsk State University, 630090 Novosibirsk, Russia \\ ${ }^{3}$ Tomsk Polytechnic University, 634050 Tomsk, Russia
}

\begin{abstract}
Experimental study of liquid layers breakdown when heated locally from the substrate side was made. Water and ethanol were used as working liquids with a layer thickness of $300 \mu \mathrm{m}$. Basic steps of the breakdown process were found and mean velocities of the dry spot formation were determined; the values are $0.06 \mathrm{~mm} / \mathrm{sec}$ for ethanol and $5.15 \mathrm{~mm} / \mathrm{sec}$ for water. The formation of residual layer over the hot-spot before the breakdown has been found for both liquids. The creation of a droplet cluster near the heating region is observed when using water as a working fluid. It was shown that evaporation is one of the general factors influencing the process of layer breakdown and dry spot formation as well as thermocapillary effect.
\end{abstract}

\section{Introduction}

Investigation of heat removal from the local heat source is currently one of the most complex problems in thermophysics due to its direct connection to the problem of microelectronic equipment cooling [1]. The average heat flux density on the surface of chips of commercially available computers and other electronic devices is currently known to reach $100 \mathrm{~W} / \mathrm{cm}^{2}$. Furthermore, there are limited areas of relatively small size where the heat flux density can exceed the average value by several times and reach $1 \mathrm{~kW} / \mathrm{cm}^{2}$ [2]. This effect takes place due to the design features of computer chips, where the processor cores cause the formation of "hot" spots. The highest heat release occurs in these local areas and the increased probability of heat transfer crisis takes place, leading to the loss in the chip efficiency and its destruction [3]. There are several approaches for solving the problem of heat removal from the "point" hot zones such as: the use of thermoelectric modules [4], boiling in microchannels [5] and spray cooling [6]. A similar problem also is linked with the LEDs cooling, where it is necessary to remove high heat flux from the local heat sources. One of the most promising methods for cooling of the electronic equipment is technology that uses processes with phase transformation. It is, for example, evaporation of a thin liquid layer, moving in a planar micro channel under the influence of the gas flow [7]. In this case the main mechanism of heat removal from the heat source is an intense

* Corresponding author: simafir94@gmail.com 
evaporation due to latent heat of vaporization. Dynamics of evaporation and, thus, the heat removal from the heat source substantially depend on the conditions in a thin layer of liquid [8]. In particular, the liquid layer rupturing due to the action of thermocapillary forces and intense evaporation leads to an aggravation of heat removal from a local heat source [9]. Thus, it is necessary to define the conditions under which the liquid layer breakup occurs.

The aim of this work is to study the breakdown dynamics of the layers under heating from a point heat source using different liquids (ethanol, water).

\section{Experimental rig}

The research was conducted on experimental rig whose scheme is presented in fig. 1. Fluid from the syringe pump enters the work area, forming a horizontal liquid layer opened to the atmosphere. The working area consists of a caprolon base, a metal substrate and a heating element. There is a local heating from the side of the substrate in the center of the horizontal liquid layer. The heating element represents a brass core with round tip of 1.6 $\mathrm{mm}$ in diameter. Caprolon base has a special notch in the upper part to mount the metal substrate and the through hole in the center with a diameter of $1.6 \mathrm{~mm}$. The metal substrate is made of stainless steel with a diameter of $50 \mathrm{~mm}$ and a thickness of $1 \mathrm{~mm}$. At the center of the substrate there is a blind hole with a diameter of $1.6 \mathrm{~mm}$ and a height of $0.8 \mathrm{~mm}$. The heating element was a brass core with round tip with a diameter of $1.6 \mathrm{~mm}$ and a height of $3 \mathrm{~mm}$. The tip is tightly inserted into the blind hole of the substrate through the base. For a better thermal contact between the heater and the substrate the thermal paste was used. The distance between the tip and the upper part of the substrate was $0.2 \mathrm{~mm}$. The heat source of the heater is a nichrome band wound on the core stem. Heating power is controlled by the power source. The heater core was placed in the notch of the base on its lower side, and between the heater and the base there was an air gap of $2 \mathrm{~mm}$. From the bottom of the heater there was an insulating material to minimize heat loss. The temperature was measured by thermocouples using measuring system NI 9214 with an accuracy of $\pm 0.1^{\circ} \mathrm{C}$. The relative humidity and the ambient air temperature are measured using the thermohygrometer Testo 645 with an accuracy of $2 \%$ and $0.1{ }^{\circ} \mathrm{C}$, respectively.

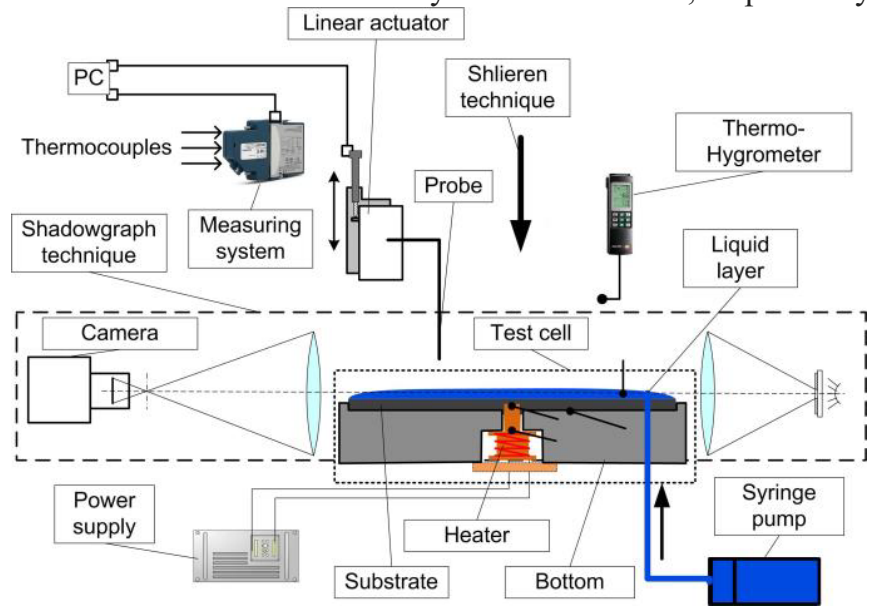

Fig. 1. Scheme of the experimental rig.

The heat flux density is determined by two different methods. The first method involves measuring the temperature difference in two different cross-sections along the length of the heater tip. For this purpose two thermocouples were mounted along the cylindrical part of the tip, and the heat flux density is calculated according to the formula: 


$$
q_{1}=\lambda \Delta T / l
$$

where $\lambda$ is the thermal conductivity of the heater material, $\mathrm{W} / \mathrm{cm} \cdot \mathrm{K} ; l$ is the distance between the two sections of the heater tip, $\mathrm{cm}$; and $\Delta T$ is the temperature difference in two cross sections along the length of the heater tip, K. The second method includes determining the power of Joule heat according to the formula:

$$
q_{2}=U I / S \text {, }
$$

where $U$ is the voltage, $\mathrm{V} ; I$ is the current intensity, A; and $S$ is the section area of the heater tip, $\mathrm{cm}^{2}$. While increasing the heat flux the difference between the methods increases up to $20 \%$. This difference arises due to heat loss, the value of which is expected for such experiments. The main method for measuring the heat flux density is considered to be the first method as the most accurate.

To control the liquid layer thickness we use the shadowgraph method and the linear actuator with the probe. With the help of high-precision syringe pump we select the flow rate, which ensure a constant level of liquid, taking into account the evaporation. In the experiment, the liquid level was maintained 5-10 $\mu \mathrm{m}$ below the probe. The horizontal layer surface and the probe are observed using video camera Imaging Source DFK 23GP031 with a resolution of $2592 \times 1944$ pixels. To visualize surface deformations and register the breakdown we use an optical schlieren system with high-speed video camera Photron FASTCAM 675K-M3 (speed of $2500 \mathrm{fps}$ at a resolution of 640x640 pixels and a scale of $25 \mu \mathrm{m} /$ pix). The working section is mounted in horizontal position using a goniometer. The surface roughness of the substrate was determined by profilometer "Micro Measure 3D station" and the average roughness value amounted to $\mathrm{R}_{\mathrm{a}}=0.327 \mu \mathrm{m}$. The advancing contact angle on the working surface in the heating area was determined by the sitting drop method (Young-Laplace) [10] at a room temperature of $25 \pm 2^{\circ} \mathrm{C}$ and amounted to $\theta_{1}=6 \pm 1^{\circ}$ for ethanol and $\theta_{2}=76 \pm 1^{\circ}$ for water.

\section{Experimental results}

The investigation was conducted at atmospheric pressure, temperature of $28 \pm 2^{\circ} \mathrm{C}$ and relative humidity of $25 \pm 3 \%$. The used working liquids were ethanol (95\% (mass.), GOST R 51723-2001) and ultrapure water. For water purification we used the system Merck Millipore Direct-Q 3 UV, which allows providing the water of type I (ultrapure water). Characteristics of the quality of the obtained ultrapure water: resistance of $18.2 \mathrm{MO} / \mathrm{cm}$, TOC (total organic carbon) $<5 \mu \mathrm{g} / \mathrm{l}$, microorganisms $<0.1 \mathrm{CFU} / \mathrm{ml}$, pyrogens (bacterial endotoxins) $<0.001$ units. end. $/ \mathrm{ml}$; RNA $<0.01 \mathrm{ng} / \mathrm{ml}$, DNA $<4 \mathrm{pg} / \mathrm{ml}$; and particles $>$ $0.22 \mu \mathrm{m}<1$ particles $/ \mathrm{ml}$. The height of the liquid layer was $300 \mu \mathrm{m}$. For both working fluids we measured the critical heat flux density at which the breakdown of the liquid layer occurs. The value of the critical heat flux density for ethanol equals to $12.6 \mathrm{~W} / \mathrm{cm}^{2}$ at the substrate temperature in the heating area of $37.1^{\circ} \mathrm{C}$, for water it is $117 \mathrm{~W} / \mathrm{cm}^{2}$ at the substrate temperature of $133^{\circ} \mathrm{C}$, respectively.

It was found out that for both working liquids the layer breakdown occurs according to one scenario [11]. First, a thermocapillary deformation of the layer above the point heating area appears (fig. 2a, b). Further thinning leads to the formation of a residual liquid layer in the area of the point heating, fig. 2c [12]. Then, the residual liquid layer evaporates to a critical thickness, at which the layer breakdown takes place, fig. $2 \mathrm{~d}$. After the breakdown the entire heating area is intensely dried, and the round dry spot is formed, fig. 2e.

The average rate of dry spot formation was measured for two working fluids and was determined as the ratio of the characteristic radius of the resulting dry spot to the time of its formation in the heating area. The time of dry spot formation is counted from the moment of the residual layer breakdown to its complete evaporation. The average rate of dry spot formation for ethanol is $0.06 \mathrm{~mm} / \mathrm{s}$, and for water it is $5.15 \mathrm{~mm} / \mathrm{s}$, respectively. The time of 
dry spot formation for ethanol as a working fluid is 7.85 seconds, and for water it is 0.13 seconds. The difference in the breakdown rates is first of all connected with different rate of the residual layer evaporation, which directly depends on the heat flux density and the substrate temperature. In addition, it is influenced by the difference in properties and hydrodynamic parameters of working fluids: contact angles and surface tension.

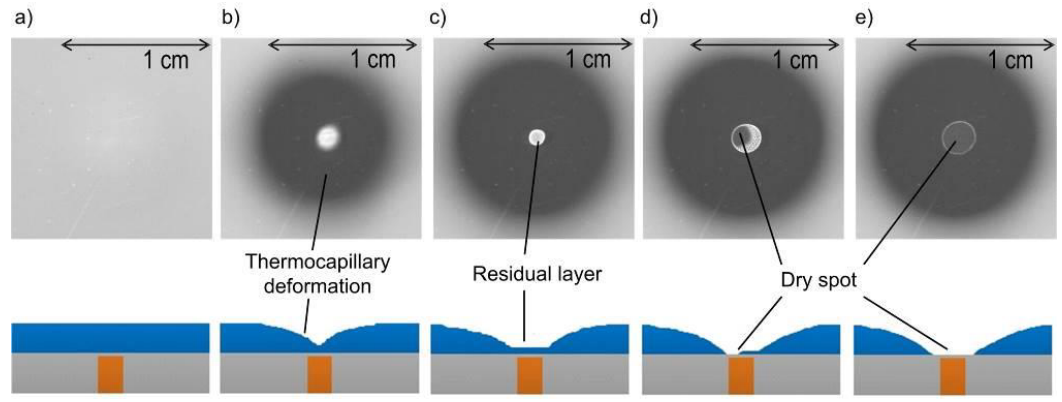

Fig. 2. The dynamics of the liquid layer breakdown in case of point heating. Liquid is ethanol and the layer height is $300 \mu \mathrm{m}$.

In the study of thermocapillary breakdown of the water layer with point heating the existence of the droplet cluster was found, fig. 3. The phenomenon of droplet cluster was investigated in detail in [13-15]. Experiments show that the droplet cluster is always formed near the heating area and practically does not influence the dynamics of the liquid layer breakdown.
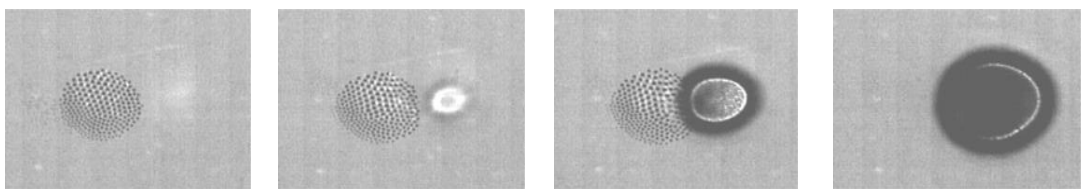

Fig. 3. Visualization of the droplet cluster and the breakdown dynamics. The liquid is water and the layer height is $300 \mu \mathrm{m}$.

\section{Conclusions}

Experiments have been performed to measure the critical heat flux and to visualize the breakdown dynamics of thin layers of ethanol and water using schlieren technique. The water layer breakdown was found to require a heat flux density by an order exceeding the critical heat flux density for a layer of ethanol of the same thickness. At that, times and the characteristic breakdown rates differ by two orders of magnitude, which is directly related to the difference in the critical heat fluxes and intensities of evaporation. It is shown that before the breakdown the residual layer appears in the area of local heating. When using water as the working liquid the formation of a droplet cluster may be observed in the vicinity of the heating area of the substrate. Along with the thermocapillary effect, evaporation is one of the main factors influencing the residual liquid layer breakdown and dry spots formation in the heating area.

\section{Acknowledgments}

The study was financially supported by the Russian Science Foundation (Project 14-1901755). 


\section{References}

1. A. Bar-Cohen, P. Wang, J. Heat Transf. 134, 5 (2012)

2. R. Mahajan, C. Chiu, G. Chrysler, Proc. IEEE 94, 8 (2006)

3. A. Watwe, R. Viswanath, Proc. Inter PACK'03 (2003)

4. A. Bar-Cohen, P. Wang, Microgr. Sc. Tech. 21 (2009)

5. P. Di Marco, W. Grassi, Int. J. Therm. Sci. 41 (2002)

6. E.A. Silk, E.L. Golliher, R.P. Selvam, Energy Convers. Manag. 49 (2008)

7. O.A. Kabov, D.V. Zaitsev, V.V. Cheverda, A. Bar-Cohen, Exp. Therm. Fl. Sc. 35, 5 (2010)

8. A.A. Fedorets, I.V. Marchuk, O.A. Kabov, Int. Phen. Heat Transf. 1, 1 (2013)

9. D.V. Zaitsev, O.A. Kabov, Microgr. Sc. Tech. $3 / 4$ (2007)

10. I.V. Marchuk, V.V. Cheverda, P.A. Strizhak, and O.A. Kabov, T. A. 22, 3 (2015)

11. Yu.V. Lyulin, S.E. Spesivtsev, I.V. Marchuk, O.A. Kabov, Tech. Ph. Let. 41, 11 (2015)

12. D.V. Zaitsev, D.A. Rodionov, O.A. Kabov, Microgr. Sc. and Tech. 19 (2007)

13. A.A. Fedorets, I.V. Marchuk and O.A. Kabov, Tech. Ph. Let. 37 (2011)

14. A.A. Fedorets, I.V. Marchuk and O.A. Kabov, JETP Let. 99, 5 (2014)

15. A.A. Fedorets, I.V. Marchuk, P.A. Strizhak and O.A. Kabov, T. A. 4 (2015) 